\title{
Chromatographic Study on the Essential Oil of Tetraclinis Articulata Vahl Masters from Morocco
}

\section{Bourkhiss $^{1 *}$, A Chaouch ${ }^{2}$, M Ouhssine ${ }^{2}$, B Bourkhiss ${ }^{2}$ and J Costa ${ }^{3}$}

${ }^{1}$ Département de Physique-Chimie, Centre Régional des Métiers de l'Éducation et de la Formation (CRMEF), Morocco

${ }^{2}$ Laboratoire de Biotechnologie Microbienne, Département de Biologie, UFR Amélioration et Transformation Microbienne et Végétale, Faculté des Sciences, Université Ibn Tofaïl, Morocco

${ }^{3}$ Laboratoire de Chimie des Produits Naturels, Université de Corse, France

*Corresponding Author: M Bourkhiss, Département de Physique-Chimie, Centre Régional des Métiers de l'Éducation et de la Formation (CRMEF), Morocco.

Received: March 20, 2019; Published: May 16, 2019

DOI: $10.31080 /$ ASPS.2019.03.0283

\section{Abstract}

With a view to contributing to the evaluation of Moroccan flora through the identification of new potentially interesting at a biological and therapeutic level, we have indertaken a study of the essential oil in the sawdust wood of the Tetraclinis articulata Vahl Masters from the Khemisset region (north-west Morocco). The study of the sawdust's essential oil, completed by GC and GC/MS, identified 22 components, the main five being: $\alpha$-acorénol (20.9\%), cédrol (17.9\%), totarol (8.8\%), $\alpha$-cédrène (8.7\%) and $\beta$ - acorénol (7.4\%). This essential oil was fractionated on an open silica column using an eluent of increasing polarity. Five fractions were collected in this way.The fraction (FH) eluted with the pentane comprised sesquiterpene hydrocarbons whereas the four oxygenated fractions (F01 to F04) eluted with a diethyl oxide/pentane mix of increasing polarity were dominated by a diterpene phenol and two sesquiterpene alcohols respectively: totarol in the F01 (42.4\%), $\alpha$-acorénol in the F02 (34.9\%) and F03 (54.0\%), and cédrol in the F04 (58.2\%). The fractionation of the oil has allowed us to concentrate constituents likely to be valued for their biological and organoleptic properties.

Keywords: Tetraclinis articulata (Vahl) Masters; Essential Oils; Chemical Composition; Flash Chromatography; Cedrol; $\alpha$-Acorenol; Totarol; CC; CG; CG-MS

\section{Introduction}

Tetraclinis articulata Vahl Masters (Cupressaceae), also known as Thuja articulata or Barbary thuya, is endemic to the south western Mediterranean, with two small outlying populations on Malta, and near Cartagenain southeast Spain [1]. This tree is an important element of the Maghreb vegetation (Morocco, Algeria and Tunisia), because it cover than one million hectares [2]. In morocco, it occupies an estimated area of 560670 ha [3], or more than half of the forest reserve in the world.

Algeria and Tunisia), because it cover than one million hectares [2]. In morocco, it occupies an estimated area of 560670 ha [3], or more than half of the forest reserve in the world.

In Morocco, different parts of the thuya of Barbary are used in traditional medicine principally against childhood [4], respiratory and intestinal infections, gastric pains, diabetes, hypertension [5], antipyretic, diuretic, antirheumatic and oral hypoglycemic [6].
In order to contribute to the development of the Moroccan flora and to identify new substances potentially interesting in the biological and therapeutic plans, we study the chemical composition of the sawdust wood essential oil of Tetraclinis articulata Vahl from the Khemisset region (north-west Morocco).

\section{Materials and Methods}

Plant material

Tetraclinis articulata (Vahl) Masters was collected in March 2013, in the region of Khemisset, Morroco. Voucher specimen was deposited in the herbarium of Faculty of Sciences of Meknes (Morocco). The wood composite samples were trasformed into sawdust using a laboratory.

\section{Essential oil extraction}

The dried vegetal material (100 g) were water-distillated (3h) using a Clevenger-type apparatus according to the method recommended in the European Pharmacopoeia [7]. The yield of the oil was calculated based on the dried weight of the plant material. 


\section{Oil fractionation}

The sawdust wood essential oil of Tetraclinis articulata (3417 mg) was chromatographed on a silica gel column (ICN, 200-500 $\mu \mathrm{m}, 60 \mathrm{~A})$. Five fractions were collected in this way. one hydrocarbon fraction (HF) was eluted with the pentane and four oxygenated fractions (OF1 to OF4) eluted with a diethyl oxyde/ pentane mix of increasing polarity. The experimental conditions were reported in Figure 1.

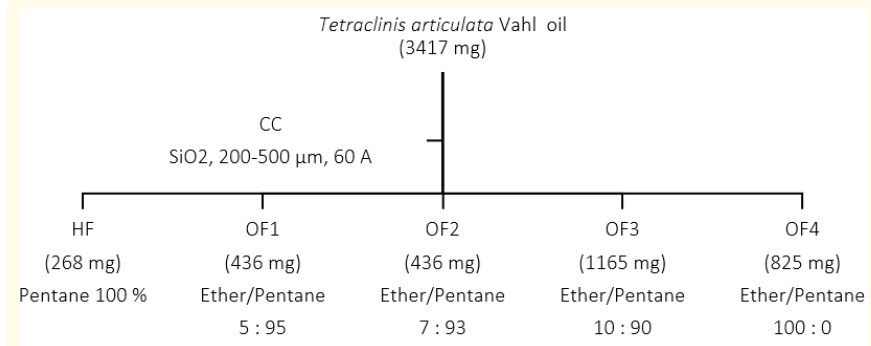

Figure 1: Fractionation of sawdust wood essential oil of Tetraclinis articulata Vahl.

\section{GC analysis}

GC analysis were carried out using a Perkin-ElmerAutosystem XL GC apparatus equipped with dual flame ionization detection (FID) system and two fused-silica capillary columns (60 m, $0.22 \mathrm{~mm}$ I.D., film thickness $0.25 \mu \mathrm{m}$ ), Rtx- 1 (polydimethylsiloxane) and Rtx-wax (polyethyleneglycol). The oven temperature was programmed from $60^{\circ} \mathrm{C}$ to $230^{\circ} \mathrm{C}$ at $2^{\circ} \mathrm{C} / \mathrm{min}$ and then held isothermally at $230^{\circ} \mathrm{C}$ for $35 \mathrm{~min}$. Injector and detector temperature was maintained at 280 ${ }^{\circ} \mathrm{C}$. Samples were injected in the split mode (1/50), using helium as carrier gas $(1 \mathrm{~mL} / \mathrm{min})$; the injection volume was $0.2 \mu \mathrm{L}$ of pure oil. Retention indices (RI) of compounds were determined relative to the retention times of series of n-alkanes (C5-C30) with linear interpolation, using the Van den Dool and Kratz equation [8] and software from Perkin-Elmer. Component relative concentrations were calculated based on GC peak areas without using correction factors.

\section{GC-MS analysis}

Oil samples were also analysed using a Perkin-Elmer Turbo mass detector (quadrupole), coupled to a Perkin-Elmer Autosystem XL, equipped with fused-silica capillary columns Rtx-1 and Rtx-Wax.
Carrier gas: helium ( $1 \mathrm{~mL} / \mathrm{min})$, ion source temperature: $150{ }^{\circ} \mathrm{C}$, oven temperature programmed from $60^{\circ} \mathrm{C}$ to $230^{\circ} \mathrm{C}$ at $2^{\circ} \mathrm{C} / \mathrm{min}$ and then held isothermally at $230^{\circ} \mathrm{C}$ ( $\left.35 \mathrm{~min}\right)$, injector temperature: $280^{\circ} \mathrm{C}$, energy ionization: $70 \mathrm{eV}$, electron ionization mass spectra were acquired over the mass range $35-350 \mathrm{Da}$, split: $1 / 80$, injection volume: $0.2 \mu \mathrm{L}$ of pure oil.

\section{Identification of essential oil constituents}

The methodology carried out for identification of individual components was based on: i) comparison of calculated retention indices (RI), on polar and apolar columns, with those of authentic compounds or literature data [8]; ii) computer matching with commercial mass spectral libraries [9] and comparison of mass spectra with those of our own library of authentic compounds or literature data [8].

\section{Result and Discussion}

Tetraclinis articulata essential oil yield is in the order of $1,63 \%$. It is relatively high compared to some plants that are used industrially as a source of essential oils. This oil was light yellow, her odor is agreeable and balsamic.

The identification of sawdust wood essential oil components of Thuya was carried out by using GC and GC/MS. 22 components were identified amounting to $83,4 \%$ of the total oil (Table 1). $\alpha$-Acorenol $(20,9 \%)$, cedrol $(17,9 \%)$, totarol $(8,8 \%), \alpha$-cedrene $(8,7 \%)$ and $\beta$-acorénol $(7,4 \%)$ are major compounds (Figure 2).

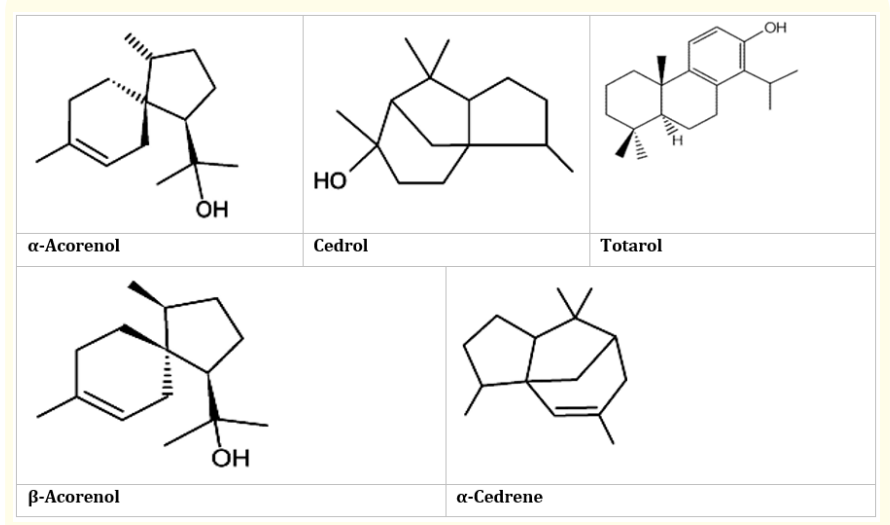

Figure 2: Major compounds of sawdust essential oil of Tetraclinis articulata Tetraclinis articulata (Vahl). 


\begin{tabular}{|l|c|c|c|c|c|c|c|c|}
\hline \multicolumn{1}{|c|}{ Compounds } & $\mathbf{R I ~ I}$ & $\mathbf{R I ~ a}$ & $\mathbf{E O}$ & $\mathbf{H F}$ & $\mathbf{O F}_{\mathbf{1}}$ & $\mathbf{O F}_{2}$ & $\mathbf{O F}_{\mathbf{3}}$ & $\mathbf{O F}_{4}$ \\
\hline Carvacrol & 1278 & 1278 & 0,8 & & & 2,9 & & \\
\hline $\boldsymbol{\alpha}$-Funebrene & 1385 & 1378 & 0,2 & 0,8 & & & & \\
\hline $\boldsymbol{\alpha}$-Cedrene & 1418 & 1413 & 8,7 & 34,4 & & & & \\
\hline $\boldsymbol{\beta}$-Cedrene & 1434 & 1419 & 3,1 & 14,6 & & & & \\
\hline Widdrene & 1434 & 1426 & 0,3 & 1,8 & & & & \\
\hline $\boldsymbol{\alpha}$-Acoradiene & 1464 & 1459 & 4,9 & 10,6 & & & & \\
\hline $\boldsymbol{\beta}$-Acoradiene & 1465 & 1461 & 3,9 & 3,9 & & & & \\
\hline $\boldsymbol{\beta}$-Alaskene & 1495 & 1490 & 0,9 & 5,6 & & & & \\
\hline Cuparene & 1498 & 1492 & 0,4 & 2,6 & & & & \\
\hline $\boldsymbol{\alpha}$-Alaskene & 1512 & 1507 & 1,9 & 11,5 & & & & \\
\hline Italicene ether & 1538 & 1521 & 0,8 & & 4,8 & 1,2 & & \\
\hline Cedrol & 1601 & 1589 & 17,9 & & & & 9,5 & 58,2 \\
\hline epi-Cedrol & 1619 & 1601 & 0,8 & & & & & 5,1 \\
\hline$\alpha$-Acorenol & 1633 & 1621 & 20,9 & & & 34,9 & 54 & 12,6 \\
\hline$\beta$-Acorenol & 1637 & 1623 & 7,4 & & & 1,1 & 9,4 & \\
\hline Isopimar-9(11),15-diene & 1906 & 1901 & 0,5 & 1,7 & & & & \\
\hline Pimara-8(14),15-diene & 1955 & 1653 & 0,3 & 0,9 & & & & \\
\hline Manoyl oxide & 1998 & 1974 & 0,2 & & 0,5 & & & \\
\hline Isopimar-7,15-diene & 1981 & 1980 & 0,4 & 0,5 & & & & \\
\hline Abietatriene & 2046 & 2032 & 0,7 & 4,6 & & & & \\
\hline Sandaracopimarinol & 2270 & 2243 & 0,4 & & & & & 1,5 \\
\hline Totarol & 2314 & 2280 & 8,8 & & 42,4 & 6,4 & & \\
\hline Total identified & & & 83,4 & 93,5 & 47,7 & 46,5 & 72,9 & 77,4 \\
\hline Oxygenated monoterpenes & & & 0,8 & & & 2,9 & & \\
\hline Hydrocarbon sesquiterpenes & & & 24,3 & 85,8 & & & & \\
\hline Oxygenated sesquiterpenes & & & 47,8 & & 4,8 & 37,2 & 72,9 & 75,9 \\
\hline Hydrocarbon diterpenes & & & 1,9 & 7,7 & & & & \\
\hline Oxygenated diterpenes & & & 9,4 & & 42,9 & 6,4 & & 1,5 \\
\hline
\end{tabular}

Table 1 : Chemical composition of Tetraclinis articulata essential oil and its fractions.

RIa: retention indices measured on the apolar column (Rtx-1)

RIl: retention indices from literature

Percentages are given on the apolar column except for compounds with the same Ria

EO : Essential oil ; HF : Hydrocarbon fraction ; OF1, OF2, OF3, OF4 : Oxygenated fractions

Our essence was characterized by the predominance of oxygenated sesquiterpenes $(47,8 \%)$ followed by hydrocarbon sesquiterpenes $(24.3 \%)$ and oxygenated diterpenes $(9,4 \%)$ as shown in Table 1. We can also note the presence of small amounts of hydrocarbon diterpenes $(1,9 \%)$, and oxygenated monoterpenes s $(0.8 \%)$ with total absence of Hydrocarbon monoterpenes. In addition, it should be noted that the essential oil of our essence could be a source of sesquiterpenes alcohol. This is also one of the characteristic in the majority of Cupressaceae [10]. 
When comparing our major compounds results obtained of Tetraclinis articulata wood with from two other Moroccan localities: Eassouira and Tetouan [11,12] located respectively in the Southwest and north of Morocco (Table 2). we noted a significant difference in composition and yield; in the case of Khemisset and Essaouira; $\alpha$-Cedrene, cedrol and $\beta$-Acorenol were considered as the principal constituents, Khemisset is also rich in totarol and Essaouira in carvone. Where as for Tetouan these components were present at $0,1 \%, 28,2 \%$ and to trace respectively. epi-Cedrol and p-Methoxythymol which were found to be the major components in Tetouan are present in small quantities or to trace in Khemisset and Essaouira.To our knowledge, this is the first study showing a relatively high abundance of $\alpha$-acorenol, $\beta$-acorenol and totarol in essential oils wood of Tetraclinis articulata. Thus it would seem that a strong chemical diversity between the essential oils of different populations.

\begin{tabular}{|l|c|c|c|}
\hline \multicolumn{1}{|c|}{ Compounds } & Khemisset & Essaouira & Tetouan \\
\hline$\alpha$-Cedrene & 8,7 & 6,6 & 0,1 \\
\hline Cedrol & 17,9 & 12,1 & 28,2 \\
\hline epi-Cedrol & 0,8 & 1,0 & 17,9 \\
\hline$\alpha$-Acorenol & 20,9 & - & 0,2 \\
\hline$\beta$-Acorenol & 7,4 & 20,4 & - \\
\hline Totarol & 8,8 & - & 0,5 \\
\hline Carvenone & - & 6,5 & - \\
\hline p-Methoxythymol & - & - & 5,4 \\
\hline
\end{tabular}

Table 2: Comparison of the major components of sawdust wood essential oil of Tetraclinis articulata from different localities of Morocco.

Thereafter, Tetraclinis articulata essential oil (3417 mg) was chromatographed by an automatized flash chromatography system (Figure 1). The fractionation led one hydrocarbon fraction HF (268 mg) and four oxygenated fractions (OF1 to OF4) representing respectively 8,6\% (268 $\mathrm{mg}$ ), 13,9\% (436 mg), 13,9\% (436 mg), 37,2\% (1165 mg) and 26,4\% (825 mg) of the total chemical composition of the essential oil (Table 1). All fractions were also analyzed by using GC and GC/MS. The fraction HF was dominated mainly by $\alpha$-cedrene (EO: $8,7 \%$, HF: $34,4 \%$ ) while the oxygenated fractions are characterized by high content of alcohols terpenic: totarol (EO: 8,8\%; OF1: 42,4\%), $\alpha$-acorenol (EO: 20,9\%;
OF2: 34,9\%; O F3: 54,0\%) and cedrol (HE: 17,9\%; OF4: 58,2\%). Thus, the fractionation has led to the separating and concentrating the major compounds ( $\alpha$-cedrene, totarol, $\alpha$-acorenol and cedrol) of the essential oil with a level of concentration.

\section{Conclusion}

The study of chemical composition of sawdust wood essential oil of Tetraclinis articulata may draw the following conclusions:

- Chemical analysis shows that $\alpha$-Acorenol (20,9\%), cedrol $(17,9 \%)$, totarol $(8,8 \%), \alpha$-cedrene $(8,7 \%)$ and $\beta$-acorénol $(7,4 \%)$ were the main components of wood global essen tial oil of thuya.

- Tetraclins articulata wood essential oil was characterized by the predominance of sesquiterpenes $(72,1 \%)$ and diterpenes $(11,3 \%)$.

- The flash chromatography has led to the separating and concentrating the major compounds ( $\alpha$-cedrene, totarol, $\alpha$-acorenol and cedrol) of sawdust our oil with a level of concentration likely to be valued for their biological and organoleptic properties.

\section{Bibliography}

1. Achhal A., et al. "Productivité du thuya (Tetraclinis articulata (Vahl) Masters) dans le bassin versant du N'fis. Ecologia Mediterraea. Tome XI. Fascicule 2/3 (1985).

2. Haddad A., et al. "Caractéristiques papetières de la pâte de bois de Thuya de Berberie (Algérie) (Tetraclinis articulata Vahl) obtenue par un procédé soude-anthraquinone". Annals of Forest Science 63 (2006): 493-498.

3. AEFC. Inventaire National Forestier. Maroc (1994).

4. M Bourkhiss., et al. Physical and Chemical News 35 (2017): 128- 132.

5. Ziyyat A., et al. "Phytotherapy of hypertension and diabetes in oriental Morocco". Journal of Ethnopharmacology 58.1 (1997): 45-54.

6. R Claisse, Pharmacopée traditionnelle au Maroc: marché populaire de Yacoub El Mansour. Actes du Premier Colloque Européen d'Ethnopharmacologie (1990): 448-449. 
7. European Pharmacopoeia. "Council of Europe". Strasbourg, 3rd edition (1997): 121.

8. H Dool and P Kratz. Journal of Chromatography A 11 (1963): 463.

9. D Joulain and König WA. "The atlas of spectral data of sesquiterpene hydrocarbons". EbVerlag Hamburg. (1998).

10. Runeberg J. The chemistry of the order Cupressales. 27. Heartwood constituents of Juniperus utahensis Lemm. Acta Chemica Scandinavica 14 (1960): 797-804.

11. Satrani B., et al. "Composition chimique et activité antibactériennes et antifongique de l'huile essentielle extraite du bois de Tetraclinis articulata du Maroc". Annales des falsifications et de l'expertise chimique et 964 (2004): 75-84.

12. Barréro AF., et al. "Chemical composition of essential oils of leaves and wood of Tetraclinis articulata (Vahl) Masters". Journal of Essential Oil Research 17 (2005): 166-167.

\section{Volume 3 Issue 6 June 2019}

(C) All rights are reserved by $M$ Bourkhiss., et al. 